\title{
Polo-Box Domain Inhibitor Poloxin Activates the Spindle Assembly Checkpoint and Inhibits Tumor Growth in Vivo
}

\author{
Juping Yuan, ${ }^{*}$ Mourad Sanhaji, ${ }^{*}$ Andrea Krämer, ${ }^{*}$ \\ Wolfgang Reindl, ${ }^{\dagger}$ Matthias Hofmann, ${ }^{\ddagger}$ \\ Nina-Naomi Kreis, ${ }^{*}$ Brigitte Zimmer, ${ }^{*}$ \\ Thorsten Berg, ${ }^{\dagger \S}$ and Klaus Strebhardt* \\ From the Departments of Gynecology and Obstetrics* and \\ Dermatology and Venerology, ${ }^{\ddagger}$ School of Medicine, J.W. Goethe- \\ University, Frankfurt; the Department of Molecular Biology, ${ }^{\dagger}$ Max \\ Planck Institute of Biochemistry, and the Center for Integrated \\ Protein Science Munich, Martinsried; and the Institute for \\ Organic Chemistry, ${ }^{\S}$ University of Leipzig, Leipzig, Germany
}

Polo-like kinase 1 (Plk1) is widely established as one of the most promising targets in oncology. Although the protein kinase domain of Plk1 is highly conserved, the polo-box domain (PBD) of Plk1 provides a much more compelling site to specifically inhibit the localization and target binding of Plk1. We recently identified, via fluorescence polarization assay, the natural product derivative, Poloxin, as the first smallmolecule inhibitor specifically targeting the function of the Plk1 PBD. In this study, we characterized its mitotic phenotype and its function in vitro and in vivo. Poloxin induces centrosome fragmentation and abnormal spindle and chromosome misalignment, which activate the spindle assembly checkpoint and prolong mitosis. Notably, centrosomal fragmentation induced by Poloxin is partially attributable to dysfunctional Kizuna, a key substrate of Plk1 at centrosomes. Moreover, Poloxin strongly inhibits proliferation of a panel of cancer cells by inducing mitotic arrest, followed by a surge of apoptosis. More important, we report, for the first time to our knowledge, that the PBD inhibitor, Poloxin, significantly suppresses tumor growth of cancer cell lines in xenograft mouse models by lowering the proliferation rate and triggering apoptosis in treated tumor tissues. The data highlight that targeting the PBD by Poloxin is a powerful approach for selectively inhibiting Plk1 function in vitro and in vivo. (Am J Pathol 2011, 179:2091-2099; DOI: 10.1016/j.ajpath.2011.06.031)
Polo-like kinases (PIks) are a family of Ser-Thr kinases regulating a variety of functions during the cell cycle and proliferation, from yeast to mammals. ${ }^{1,2}$ In mammalian cells, three closely related members (ie, Plk1, Plk2/Snk, and Plk3/Prk) and one distantly related kinase (ie, Plk4/ Sak) have been identified, with apparently different expression patterns and physiological functions. Recently, mouse Plk5 has also been identified and human Plk5 is an interesting member lacking the protein kinase domain, ${ }^{3}$ which is implicated in specific roles in neuron differentiation and glioblastoma suppression. ${ }^{4}$ Plk1, the most thoroughly characterized member among the mammalian Plks, has multiple important functions during mitosis. ${ }^{1,5}$ In line with this multitude of proposed functions, Plk1 localizes to diverse mitotic structures, including centrosomes, kinetochores, the central spindle, and the midbody. ${ }^{1,6-8}$ Structurally, in addition to the conserved protein kinase domain, the members of the Plk family share, at the C-terminus, a conserved region termed the polobox domain (PBD), which is essential for substrate targeting and Plk1 localization. The PBD, comprising two polo-box motifs, constitutes a binding region with maximal affinity to phosphopeptides containing a consensus sequence S-pS/pT-P/X. ${ }^{9,10}$

Plk1 is highly expressed in a broad spectrum of cancer types, and its expression often correlates with poor prognosis, suggesting its involvement in oncogenesis and its potential as a therapeutic target. ${ }^{11}$ Overexpression of

Supported by grants from Deutsche Krebshilfe (107594 and 108553), BANSS Stiftung and LOEWE präbionik grants (BOSS 4 to M.H.) W.R. and T.B. were supported by the Department of Molecular Biology (director, Dr. Axel Ullich) at the Max Planck Institute of Biochemistry, Martinsried.

Accepted for publication June 3, 2011

T.B. and K.S. contributed equally to this work.

Supplemental material for this article can be found at http://ajp. amjpathol.org or at doi: 10.1016/j.ajpath.2011.06.031.

Current address of W.R.: Life Sciences Division, Lawrence Berkeley National Lab, Berkeley, California.

Address reprint requests to Juping Yuan, M.D., or Klaus Strebhardt, Ph.D., Department of Gynecology and Obstetrics, School of Medicine J.W. Goethe-University, Theodor-Stern-Kai 7, 60590 Frankfurt, Germany. E-mail: yuan@em.uni-frankfurt.de or strebhardt@em.uni-frankfurt.de. 
Plk1 in human tumor cells, but not in normal nondividing cells, makes it an attractive and selective target for molecular intervention. Over the years, efforts have been made to identify PIk1 inhibitors, yielding several potent compounds that competitively inhibit the catalytic activity of Plk $1 .{ }^{11}$ The protein kinase domain of Plk 1 is closely related to several members of the superfamily of protein kinases, whereas the PBD is unique and a specific signature of the Plk kinase family. Moreover, although Plk 1 is strongly associated with oncogenic transformation, ${ }^{11,12}$ PIk2 and PIk3 are critical for checkpoint-mediated cell cycle arrest to ensure genetic stability and prevent oncogenic transformation. ${ }^{13-15}$ Thus, the ideal inhibitor should selectively target the PBD of PIk1 but not that of Plk2 and Plk3.

Based on a fluorescence polarization assay, we have recently identified the natural product thymoquinone (TQ) and its synthetic derivative Poloxin as the first small-molecule inhibitors targeting the PBD of Plk $1 .{ }^{16}$ We have shown that Poloxin exhibits a high specificity toward the PBD of Plk1, reduces both centrosomal and kinetochoral localization of Plk1, induces chromosome congression defects, arrests cells in prometaphase, and triggers further apoptosis in HeLa cells. The data demonstrate that inhibition of the PBD is sufficient to interfere with some of the mitotic functions of PIk1, including chromosome congression and mitotic progression. Herein, we analyzed the Poloxininduced phenotype in more detail, its efficacy in various cancer cell lines, and its effect on proliferation using xenograft mouse models.

\section{Materials and Methods}

\section{Cell Culture and Synchronization}

All cell lines were grown according to the supplier's suggestions (DSMZ, Braunschweig, Germany). HeLa 776-6 and HeLa P25 cells were established as previously described. ${ }^{17-19}$ Briefly, HeLa cells transfected with plasmids $\mathrm{phH} 1 / \mathrm{shRNA} /$ cyclin B1 or Plk1 were selected with medium containing G418 for 6 weeks. Cell clones with various levels of cyclin B1 or Plk1 were obtained. Cell synchronization to the $G_{1}-S$ boundary was performed by double thymidine block, as previously described. ${ }^{17}$

\section{Western Blot Analysis and Indirect Immunofluorescence Staining}

These experiments were performed as previously described. ${ }^{17,19,20}$ The following antibodies were used for Western blot analysis: mouse monoclonal antibodies against caspase-3, caspase-9, and Cdc25C (Santa Cruz Biotechnology, Heidelberg, Germany); rabbit polyclonal antibodies against poly(ADP)ribose polymerase (Cell Signaling, Beverly, MA); mouse monoclonal antibodies against $\beta$-actin (Sigma-Aldrich, Taufkirchen, Germany); and secondary anti-mouse or anti-rabbit antibodies (Santa Cruz Biotechnology). The following primary antibodies were used for staining: rat polyclonal anti- $\alpha$-tubulin (Biozol, Eching,
Germany), rabbit polyclonal antibodies against pericentrin (Cell Signaling), mouse monoclonal anti-phospho-histone H3 (p-HH3, or Ser10; Millipore, Schwalbach, Germany), mouse monoclonal anti-Plk1 (Santa Cruz Biotechnology), rabbit polyclonal-anti-Plk1 (Millipore), mouse monoclonal antibodies against BubR1 (BD Biosciences, Heidelberg), human anti-centromere antibody (ImmunoVision, Springdale, AR), and mouse anti- $\gamma$-tubulin (Abcam, Cambridge, $P A)$. Fluorescein isothiocyanate-conjugated donkey antimouse, Cy3-conjugated goat anti-rabbit, or anti-rat and Cy5-conjugated goat anti-mouse (Jackson Immunoresearch, West Grove, PA) were used as secondary antibodies.

The assays for cell cycle analysis, cell viability assay, annexin staining, and activity of caspase- $3 / 7$ were performed as previously described. ${ }^{17,19}$

\section{In Vivo Experiments, Western Blot Analysis, and IHC with Tumor Tissue}

Viable MDA-MB-231 or HeLa cells $\left(1 \times 10^{6}\right)$ were resuspended in $300 \mu \mathrm{L}$ of $0.9 \% \mathrm{NaCl}$ and s.c. injected into both flanks of nude mice (MDA-MB-231: $n=8$ mice in each group, total $N=16$; HeLa: $n=7$ mice in each group, total $N=14$ ). Approximately 3 weeks after inoculation, mice were treated with Poloxin $(40 \mathrm{mg} / \mathrm{kg}$ ) or TQ (20 $\mathrm{mg} / \mathrm{kg}$ ) by intratumoral injection on Mondays, Wednesdays, and Fridays for 5 to 6 weeks. The tumor area was calculated by multiplication of the greatest diameter with the perpendicular diameter every 2 to 3 days. Measurements of all tumors within the group were represented by the mean value. $U$-tests and Student's $t$-tests were performed for statistical evaluation among MDAMB-231 groups and between HeLa groups, respectively. All mice were properly treated in accordance with the guidelines of the local animal committee.

Cellular extracts from tumor tissues were prepared by using standard protocol. Briefly, tumor pieces were digested in lysis buffer [50 mmol/L HEPES (pH 7.5), 150 $\mathrm{mmol} / \mathrm{L} \mathrm{NaCl}, 1 \mathrm{mmol} / \mathrm{L}$ EDTA, $2.5 \mathrm{mmol} / \mathrm{L}$ EGTA, 10\% glycerol, $0.1 \%$ Tween $20,1 \mathrm{mmol} / \mathrm{L}$ dithiothreitol, 10 $\mathrm{mmol} / \mathrm{L} \beta$-glycerol-phosphate, $1 \mathrm{mmol} / \mathrm{L} \mathrm{NaF}$, and 0.1 $\mathrm{mmol} / \mathrm{L} \mathrm{Na}_{3} \mathrm{VO}_{4}$ with Complete Protease Inhibitor Cocktail; Roche, Mannheim, Germany] and then homogenized. After a 30-minute incubation on ice, the lysates were centrifuged with $10,000 \times g$ at $4^{\circ} \mathrm{C}$ for 20 minutes. Cellular extracts were obtained by a further 20-minute incubation on ice and centrifugation. Sections of formalinfixed, paraffin-embedded tissues were used for immunohistochemical $(\mathrm{IHC})$ analysis. Slides were pretreated in a microwave oven in $10 \mathrm{mmol} / \mathrm{L}$ citrate buffer to improve antigen retrieval. Monoclonal mouse anti-human Ki-67 antibodies (Dako, Glostrup, Denmark), polyclonal rabbit anti-p-HH3 (Ser10) antibodies (Millipore), and polyclonal rabbit anti-cleaved caspase-3 antibodies (Cell Signaling) were used for staining. Sections were stained using alkaline phosphatase anti-alkaline phosphatase or avidin-biotin peroxidase complex techniques. 


\section{Results}

\section{Poloxin Induces Defects in Centrosome Integrity and Chromosome Alignment During Mitosis}

Poloxin induces mitotic arrest and prolongs the mitotic duration (see Supplemental Figure S1, A and B, at http://ajp.amjpathol.org), accompanied by Plk1's mislocalization at kinetochores and centrosomes with reduced $\gamma$-tubulin (see Supplemental Figure S2, A and B, at $h t t p: / / a j p . a m j p a t h o l . o r g)$, as previously reported, ${ }^{16}$ corroborating that Poloxin specifically targets the PBD of Plk1 in cells. To further explore the reasons for mitotic arrest, we analyzed the mitotic phenotype in more detail in Poloxin-treated HeLa cells by immunofluorescence microscopy. HeLa cells, synchronized by double thymidine block and released into medium with either $25 \mu \mathrm{mol} / \mathrm{L}$ Poloxin or dimethyl sulfoxide (DMSO) for 10 hours, were stained for $\alpha$-tubulin, pericentrin, and DNA. Strikingly, compared with DMSO-treated cells (Figure 1A), Poloxintreated mitotic cells exhibited frequently fragmented and disassociated centrosomes (pericentrin in Figure 1A), associated with aberrant mitotic spindles ( $\alpha$-tubulin in Figure $1 \mathrm{~A}$ ), which could be induced either indirectly, by perturbing microtubule nucleation due to fragmented centrosomes, or directly, by interfering with tubulin-stabilizing proteins, such as traditionally controlled tumor protein ${ }^{21,22}$ in Poloxin-treated cells. In addition, consistent with our previous results, defects in chromosome alignment were easily observable (ie, unaligned chromosomes surrounding the metaphase plate; DAPI in Figure 1A). Further analysis revealed that almost $50 \%$ of the $25 \mu \mathrm{mol} / \mathrm{L}$ Poloxin-treated cells displayed abnormal mitotic spindles (Figure 1B), 37\% showed defects in chromosome alignment (Figure 1C), and almost 60\% exhibited centrosomal fragmentation (Figure 1D) during mitosis. In addition, we performed the same experiment in colon cancer HCT116 p53-- cells, which enter mitosis despite cellular stress. Fragmented centrosomes in mitotic cells were $7 \%$ for DMSO-treated and $31 \%$ for 25 $\mu \mathrm{mol} / \mathrm{L}$ Poloxin-treated HCT116 p53 ${ }^{-1-}$ cells, respectively (see Supplemental Figure S2, C and D, at http:// ajp.amjpathol.org). The data suggest that Poloxin-treated cells face severe problems with proper spindle formation, chromosome alignment, and centrosome integrity during mitosis.

\section{Fragmented Centrosomes Induced by Poloxin Are Associated with Dysfunction of Kiz}

Centrosomal fragmentation induced by Poloxin was attracting our attention. Phosphorylation of Kizuna (Kiz) at T379 is thought important for stabilizing mitotic centrosomes. ${ }^{23}$ To answer whether Kiz was affected by Poloxin, a rescue experiment was performed, as illustrated in Figure 2A: HeLa cells were cotransfected with human Myc-tagged wild-type Kiz, its nonphosphorylatable mutant Kiz T379A, or phosphomimetic Kiz T379E and pBabe-puro constructs. After selection with puromycin, cells were synchronized and released into fresh
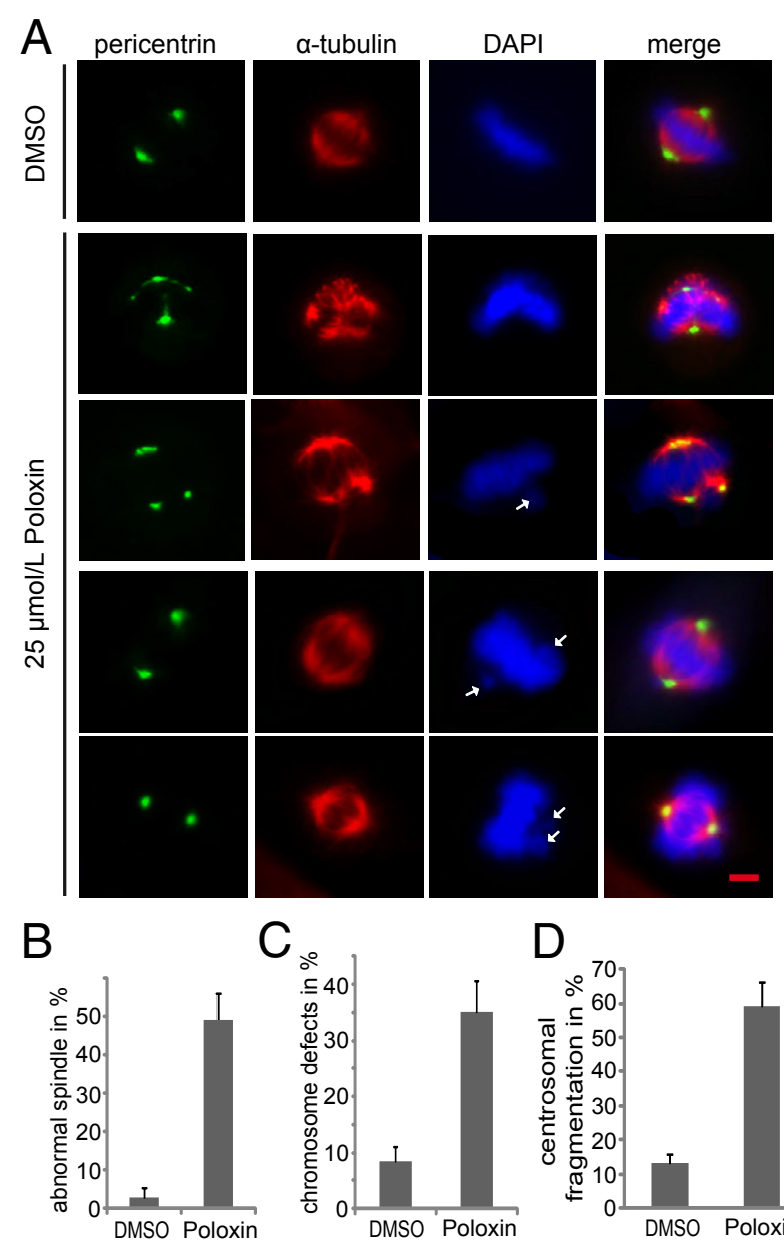

Figure 1. Poloxin induces defects in centrosome integrity, spindle formation, and chromosome alignment in mitosis. A: HeLa cells were synchronized with double thymidine block and released into fresh medium with either DMSO or $25 \mu \mathrm{mol} / \mathrm{L}$ Poloxin for 10 hours. Cells were fixed and stained for $\alpha$-tubulin, pericentrin, and DNA. The morphological features of centrosomes, spindles, and chromosomes were examined by fluorescence microscopy. Examples are displayed for centrosome fragmentation with aberrant mitotic spindles (second and third rows, pericentrin and $\alpha$-tubulin) and for misaligned chromosomes (third through fifth rows, DAPI). White arrows: Misaligned chromosome. Cells treated with DMSO were taken as control (first row). Scale bar $=5 \mu \mathrm{m}$. Quantification of abnormal spindles (B), chromosome misalignment (C), and centrosomal fragmentation (D) in approximately 300 mitotic HeLa cells treated with DMSO or $25 \mu \mathrm{mol} / \mathrm{L}$ Poloxin. The results are presented as mean $\pm \mathrm{SD}$.

medium containing either DMSO or Poloxin. Cells were then stained for immunofluorescence microscopy. Approximately $40 \%$ of treated mitotic cells showed centrosomal fragmentation with $15 \mu \mathrm{mol} / \mathrm{L}$ Poloxin treatment (Figure 2, B and C). Interestingly, although the phosphomimetic Kiz T379E was able to rescue approximately $36 \%$ of the fragmentation (Figure 2, B and C), wild-type Kiz and alanine-mutant Kiz T379A hardly affected the phenotype (Figure 2, B and C). The expression levels of Myc-tagged wild-type Kiz and its variants in HeLa cells were comparable using a Western blot analysis (Figure 2D). HeLa cells, treated as described in Figure 2A but without Poloxin, were also stained for control (see Supplemental Figure S3, A, B, and C, at http://ajp.amjpathol.org). 
A

\begin{tabular}{|c|c|c|}
\hline Day 1 & Day 2 & Day 3 \\
\hline $\begin{array}{l}\text { Kiz+pBabe-puro } \\
\text { constructs } \\
\text { cotransfection }\end{array}$ & $\begin{array}{r}\begin{array}{c}\text { puromycin } \\
\text { selection }\end{array} \\
\text { thymidine } \\
\text { block } \\
\text { for } 14 \mathrm{~h}\end{array}$ & $\begin{array}{l}\text { Release into medium } \\
\text { with DMSO or } 15 \\
\mu \mathrm{mol} / \mathrm{L} \text { Poloxin for } 10 \mathrm{~h}\end{array}$ \\
\hline
\end{tabular}

B

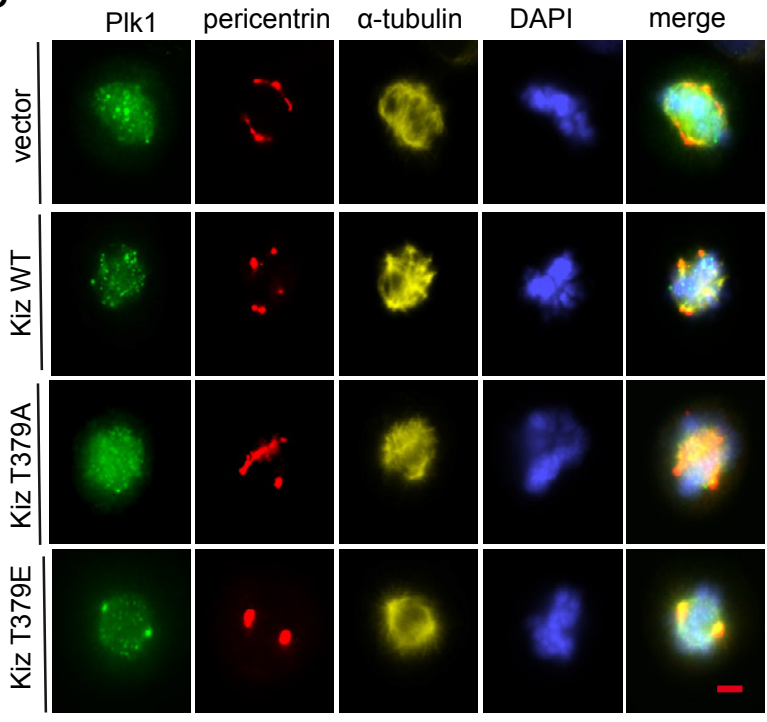

C

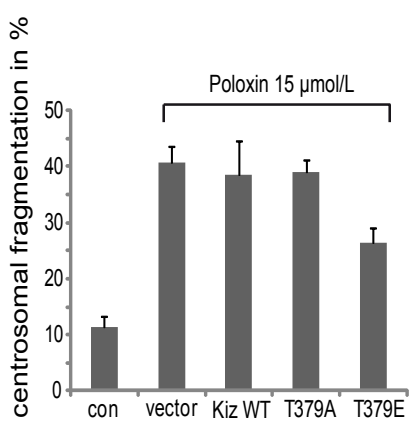

D

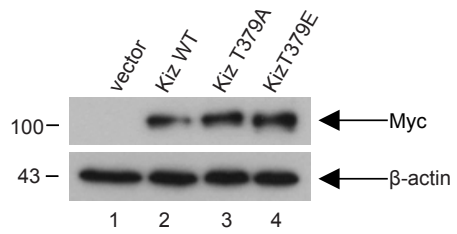

Figure 2. Centrosomal fragmentation induced by Poloxin is partially rescued by Kiz T379E. A: Working schedule. To obtain sufficient mitotic cells for analysis, HeLa cells, transfected, selected, and synchronized, were treated for 10 hours with a lower concentration of $15 \mu \mathrm{mol} / \mathrm{L}$ Poloxin, because $25 \mu \mathrm{mol} / \mathrm{L}$ Poloxin detaches HeLa cells, treated with transfection, selection, and synchronization, from the cell culture slides, along with increasing the mitotic cell population. B: HeLa cells were treated as described in $\mathbf{A}$ and stained for Plk1, pericentrin, $\alpha$-tubulin, and DNA. Cells treated with DMSO were taken as control (top row). Scale bar $=5 \mu \mathrm{m}$. C: Evaluation of centrosomal fragmentation in approximately 300 mitotic cells from each group in $\mathbf{B}$. The results are presented as mean \pm SD. con, control. D: Expression levels of Myc-tagged wild-type Kiz and its variants in HeLa cells.

\section{Poloxin Activates the Spindle Assembly Checkpoint}

Inactivation of Plk1 causes a prometaphase arrest by activating the spindle assembly checkpoint. ${ }^{24-26}$ To explore whether Poloxin is capable of activating the checkpoint, Poloxin-treated HeLa cells were stained for $\alpha$-tubu- lin, DNA, and BubR1, an important regulator of the spindle assembly checkpoint. Plk1 phosphorylates BubR1, which regulates the stability of kinetochore-microtubule interaction. ${ }^{27}$ Yet, Plk1 is not required for BubR1's localization at kinetochores in HeLa cells, ${ }^{27-29}$ although Plx1 is responsible for the loading of xBubR1 onto kinetochores in Xenopus laevis. ${ }^{28}$ In DMSO-treated cells, BubR1 localized at kinetochores before chromosome alignment in prometaphase, and it disappeared when chromosomes properly aligned at the equatorial plate in metaphase (Figure 3A). On the other hand, most of the Poloxin-treated cells were retained during prometaphase, with strong BubR1 staining at kinetochores of not yet aligned chromosomes (Figure 3A). However, strong signals of BubR1 were still bound to kinetochores in those

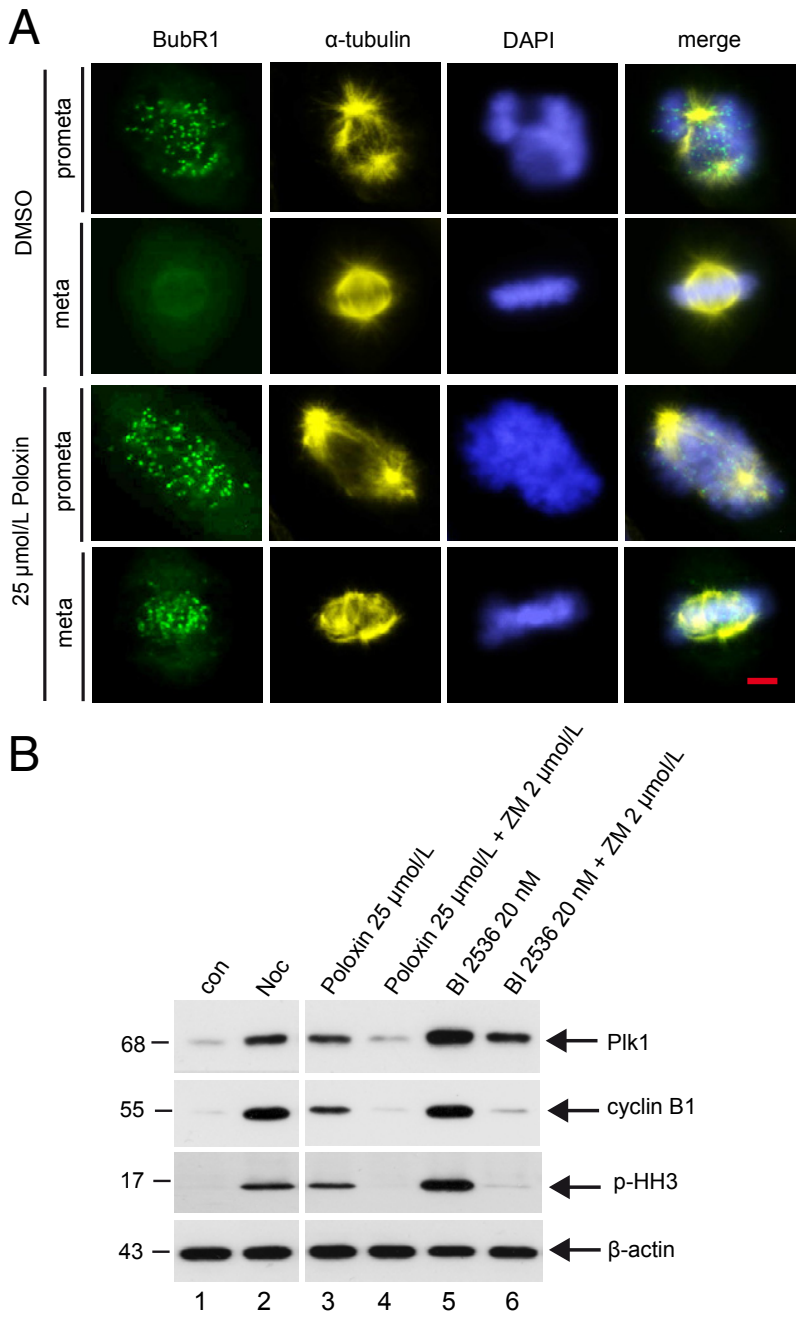

Figure 3. Poloxin activates the mitotic checkpoint. A: HeLa cells were synchronized by thymidine treatment and released into medium containing DMSO or $25 \mu \mathrm{mol} / \mathrm{L}$ Poloxin for 10 hours. Cells were stained for BubR1, $\alpha$-tubulin, and DNA. Scale bar $=5 \mu \mathrm{m}$. B: HeLa cells were synchronized by thymidine treatment and released into medium containing $25 \mu \mathrm{mol} / \mathrm{L}$ Poloxin or $20 \mathrm{nmol} / \mathrm{L}$ BI 2536. Twelve hours later, the shake-off cells were further incubated with Poloxin alone, Poloxin plus 2 $\mu \mathrm{mol} / \mathrm{L}$ ZM 447439, BI 2536 alone, or BI 2536 plus ZM 447439 for a further 2 hours, as indicated. Cellular extracts were then prepared for Western blot analyses with antibodies against Plk1, cyclin B1, and p-HH3. Nontreated (con) or nocodazole-treated (Noc) cells were taken as mitoticnegative and mitotic-positive controls, respectively. $\beta$-Actin served as the loading control. 
A

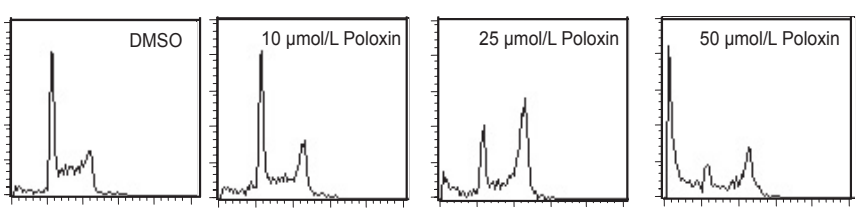

C

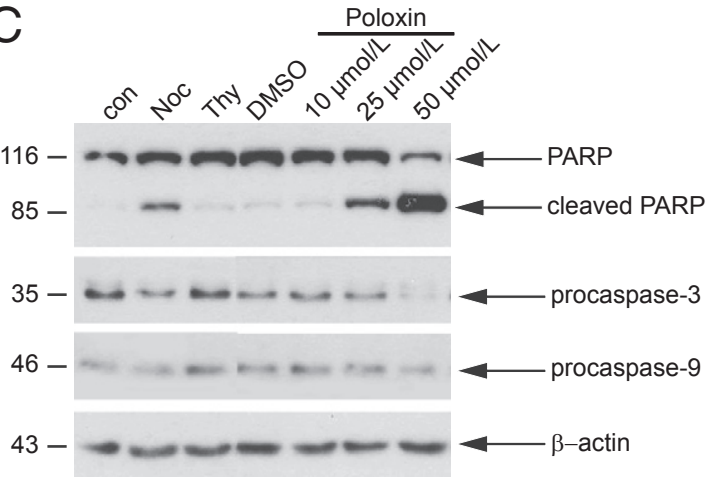

B

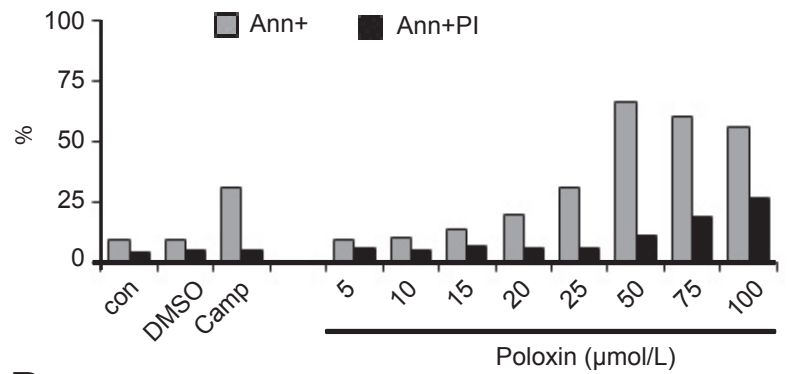

D

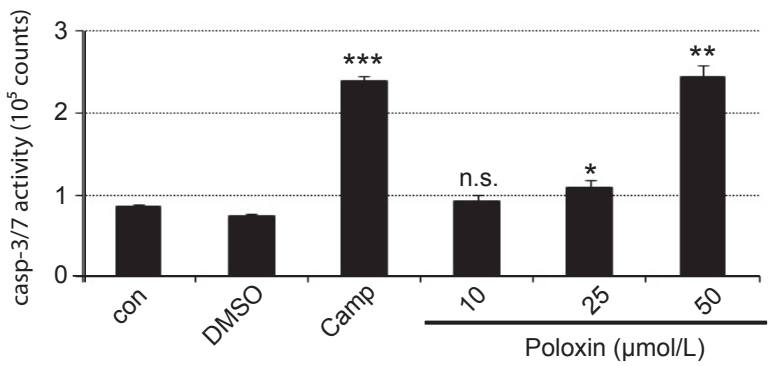

Figure 4. Poloxin induces apoptosis. A: The sub-G $\mathrm{G}_{1}$ population is increased in Poloxin-treated HeLa cells. Cells were treated with Poloxin with indicated concentrations for 24 hours and analyzed by fluorescence-activated cell sorting. B: Cells were treated with increasing concentrations of Poloxin for 24 hours and stained for annexin (Ann) and propidium iodide (PI). Cells treated with DMSO or camptothecin (Camp, $10 \mu \mathrm{mol} / \mathrm{L}$ ) were taken as negative and positive controls, respectively. C: HeLa cells were treated as indicated for 24 hours. Cellular extracts were prepared for Western blot analyses with corresponding antibodies. $\beta$-Actin served as the loading control. Cellular extracts from nontreated cells (con) or cells treated with DMSO, nocodazole (Noc), or thymidine (Thy) were taken as controls. Two lanes (the same amounts of DMSO as that in 10 and $25 \mu \mathrm{mol} / \mathrm{L}$ of Poloxin) between Thy and DMSO were omitted, and the equal amount of DMSO in $50 \mu \mathrm{mol} / \mathrm{L}$ of Poloxin remained as the DMSO control. PARP, poly(ADP)ribose polymerase. D: HeLa cells were treated as in B, and cellular extracts were prepared for active caspase-3/7 assays using the Caspase-Glo Assay (Promega, Mannheim, Germany). Cellular extracts from control (con) and DMSO- or Camp-treated cells were taken as negative and positive controls, respectively. The results are presented as the mean \pm SD $(n=3)$ and analyzed by the Student's $t$-test. ${ }^{*} P<0.05,{ }^{* *} P<0.01$, and ${ }^{* * * *} P<0.001$. n.s., no significance.

Poloxin-treated cells, which managed to reach metaphase regardless of aberrant spindles (Figure $3 A$ ). BubR1 possibly senses misattachments or reduced tensions and thereby activates the spindle assembly checkpoint in Poloxin-treated cells. To corroborate these results, HeLa cells were synchronized by thymidine treatment and released into fresh medium with 25 $\mu \mathrm{mol} / \mathrm{L}$ of Poloxin for 12 hours. The shake-off cells were then incubated with medium containing Poloxin or in combination with $2 \mu \mathrm{mol} / \mathrm{L}$ of the Aurora A/B inhibitor ZM 447439 (Tocris Bioscience, Ellisville, MO) for a further 2 hours. Poloxin-treated cells were still kept in mitosis, as evidenced by high levels of mitotic protein Plk1, cyclin B1, and p-HH3 (Figure 3B). However, in the presence of ZM 447439, the Plk1 and cyclin B1 levels were strongly reduced and the $\mathrm{p}-\mathrm{HH} 3$ signal almost disappeared (Figure 3B), implying that cells escaped the prometaphase arrest and exit from mitosis after inactivating the spindle assembly checkpoint with ZM 447439. BI 2536, an inhibitor of the protein kinase domain of Plk1, was used as a positive control (Figure 3B) because it also activates the spindle assembly checkpoint and arrests cells in prometaphase, and cells exit from mitosis on treatment with the Aurora A/B inhibitor hesperidin. ${ }^{26}$ The data suggest that the prometaphase delay induced by Poloxin is ascribed to activation of the spindle assembly checkpoint.

\section{Massive Apoptosis Caused by Poloxin}

Cancer cells with depletion/inhibition of Plk1 undergo apoptosis, mostly caused by catastrophic mitotic defects. ${ }^{30-33}$ To corroborate that inhibiting Plk1 by Poloxin triggers cancer cells to apoptosis, asynchronous HeLa cells were treated with increasing amounts of Poloxin for 24 hours and cell cycle profiles were analyzed by fluorescence-activated cell sorting. As shown in Figure 4A, Poloxin arrested cells in the $\mathrm{G}_{2} / \mathrm{M}$ phase with a distinctive sub- $G_{1}$ peak in a concentration-dependent manner, indicative of apoptosis induction after prolonged mitosis. Apoptosis induction by Poloxin was further underlined by annexin staining (Figure 4B). In addition to HeLa cells, we also measured the sub- $G_{1}$ peak and performed annexin staining in MDA-MB-231, SW 480, MCF7, and A549 cells treated with Poloxin, and comparable results were obtained (data not shown). The induction of apoptosis was further confirmed by using Western blot analyses by showing cleaved poly(ADP)ribose polymerase and reduced procaspase-3 and procaspase-9 (Figure 4C), consistent with the observation that the activities of caspase-3/7 were increased in the treated cellular extracts (Figure 4D). Furthermore, Poloxin induced the cleavage of poly(ADP)ribose polymerase in connection with increased Emi1 and decreased p-Cdc25C (see Supplemental Figure S3D at http://ajp.amjpathol.org), two 

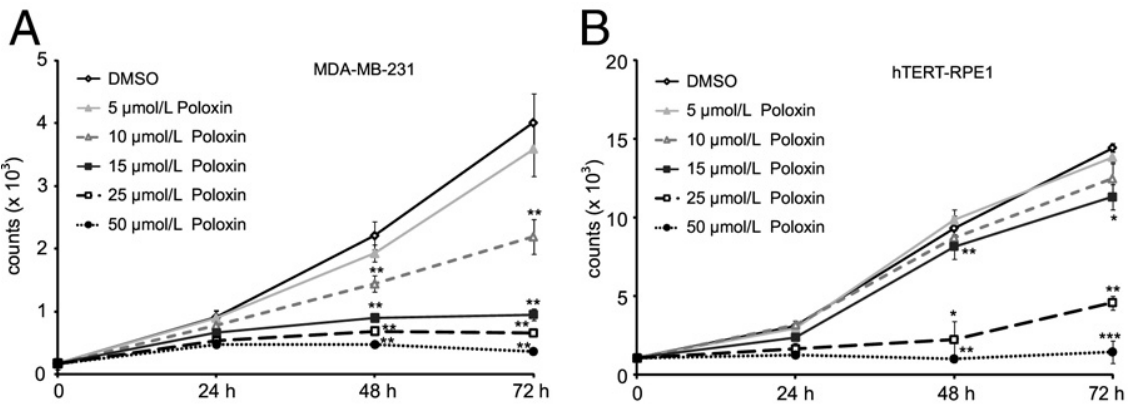

specific targets of Plk1, implying that apoptosis induction is associated with the function of Poloxin by targeting Plk1 within cells.

\section{Poloxin Inhibits Proliferation of Various Cell Types}

To study its inhibitory effect on proliferation, cancer cells from various origins were treated with increasing doses of Poloxin for different time periods. Poloxin inhibited proliferation of metastatic breast cancer MDA-MB-231 cells in a dose-dependent manner through 72 hours (Figure 5A). However, a similar inhibitory effect was also observable in human normal retinal epithelial cells (hTERT-RPE1 in Figure 5B). These dose and time kinetics were also performed in various cancer and normal cell lines, and $\mathrm{EC}_{50}$ values of all cell lines tested were illustrated in Table 1. We could not find a distinctively different response to Poloxin between cancer and normal cell lines, at least in the cell culture system, suggesting that Plk1 is required for all proliferating cells.

\section{Poloxin Inhibits Tumor Growth in Vivo}

We next investigated the ability of Poloxin to inhibit tumor growth in nude mice xenografted with MDA-MB-231 or

Table 1. Inhibitory Effect of Poloxin on Proliferation in Various Cell Lines

\begin{tabular}{lll}
\hline Cells/cell lines & \multicolumn{1}{c}{ Tissue type } & EC $_{50}(\mu \mathrm{mol} / \mathrm{L})$ \\
\hline Tumor & & \\
MCF7 & Breast & 35 \\
MDA-MB-231 & Breast & 15 \\
Detroit 562 & Pharynx & 15 \\
T47D & Breast & 25 \\
A549 & Lung & 20 \\
SW 480 & Colon & 22 \\
HCT 116 & Colon & 25 \\
HeLa & Cervix & 25 \\
HeLa P25* & Cervix & 22 \\
HeLa 776-6 & Cervix & 22 \\
PC-3 & Prostate & 20 \\
Normal & & \\
hTERT-RPE1 & Retinal epithelial & 20 \\
MTSV-1 & Mammary epithelial & 20 \\
Fibroblasts & Foreskin fibroblastic & 25 \\
HUVECs & Umbilical vein endothelial & 20 \\
\hline
\end{tabular}

*Stably Plk1-depleted HeLa.

†Stably cyclin B1-depleted HeLa.

HUVEC, human umbilical vein endothelial cell.
HeLa cells. We could observe a significant reduction of tumor volume after approximately 6 weeks of treatment with Poloxin or TQ in MDA-MB-231 xenograft mice compared with vehicle DMSO treatment (Figure 6A). Suppression of tumor growth by $\mathrm{TQ}$ was previously reported. ${ }^{34}$ Moreover, tumor regression was also observed in HeLa xenograft mice treated with Poloxin (Figure 6B). Poloxin treatment was well tolerated, as judged by body weight (see Supplemental Figure S4A at http://ajp. amjpathol.org). Furthermore, by using Western blot analysis and $\mathrm{IHC}$ staining, we showed that tumor regression of MDA-MB-231 cells after Poloxin or TQ treatment was accompanied by a decrease in proliferation rate, as evidenced by Plk1 levels (see Supplemental Figure S4, B and $\mathrm{C}$, at $h$ ttp://ajp.amjpathol.org), $\mathrm{Ki}-67$ and p-HH3 staining, and an increase in apoptosis, demonstrated by ac-
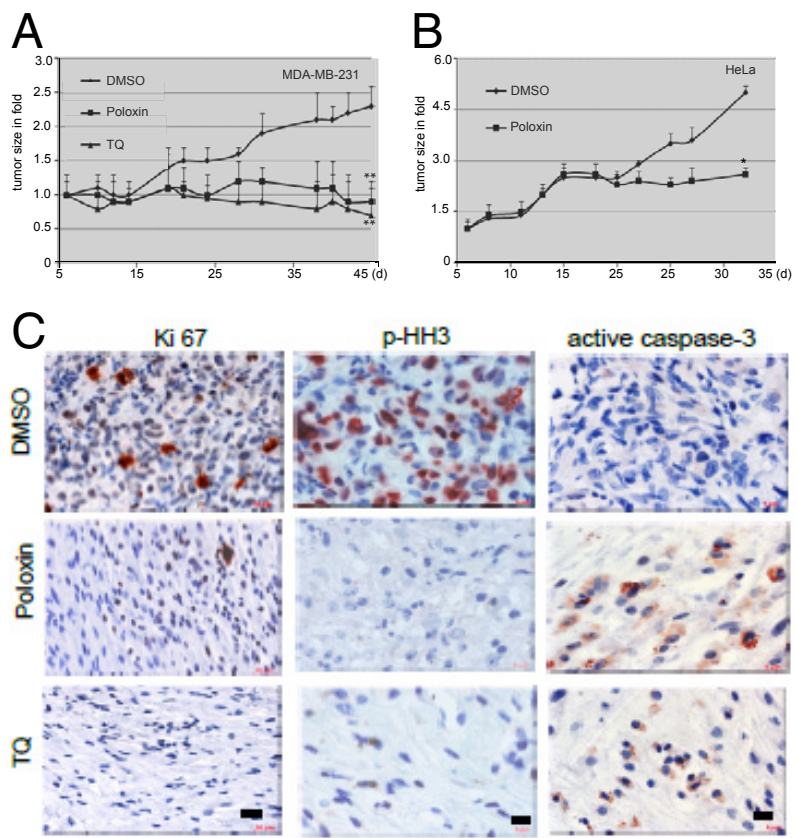

active caspase-3

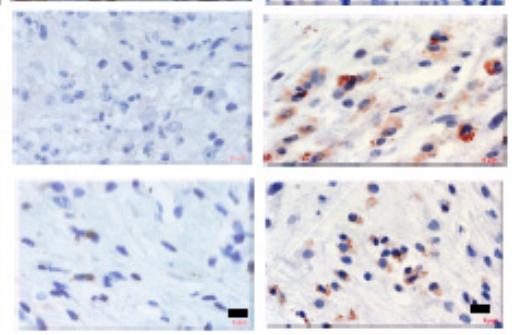

Figure 6. Poloxin suppresses tumor growth. $\mathbf{A}$ and $\mathbf{B}$ : Nude mice bearing established xenografts of MDA-MB-231 (A, $n=8$ mice in each group, $N=16$ mice per group) or HeLa cells (B, $n=7$ mice in each group, $N=14$ mice per group) were intratumorally treated with DMSO, Poloxin $(40 \mathrm{mg} / \mathrm{kg})$, or TQ $(20 \mathrm{mg} / \mathrm{kg})$ on Mondays, Wednesdays, and Fridays. Tumor size is displayed. Data are presented as the mean \pm SD and statistically analyzed by the $U$-test (A) and the Student's $t$-test (B), respectively, because of different numbers of mice in each trial. ${ }^{*} P<0.05,{ }^{* *} P<0.001$. C: IHC staining. MDA-MB-231 tumor tissues from xenograft mice treated with DMSO, Poloxin, or TQ for 6 weeks were stained for proliferation marker Ki-67 (left), mitotic marker p-HH3 (middle), or apoptosis marker active caspase-3 (right). Scale bars: 20 $\mu \mathrm{m}(\mathrm{Ki}-67) ; 10 \mu \mathrm{m}$ (p-HH3 and active caspase-3). 
tive caspase-3 staining, compared with DMSO-treated tumor tissues (Figure 6C).

\section{Discussion}

Anti-mitotic agents targeting tubulin are widely used, with effectiveness in treating cancer, but they affect both dividing and nondividing cells, inducing unwanted adverse effects. ${ }^{35}$ Therefore, the development of a new generation of anti-mitotic therapy that targets proteins with specific functions in mitosis is much desired. Plk1, the key regulator of mitosis, has been established as one of such promising candidates. In fact, several interesting Plk1 inhibitors, most of them against the protein kinase domain of Plk1, are being tested in clinical trials, as recently summarized. ${ }^{5,36-38}$ In a more selective manner to the widely conserved kinase domain, the PBD of Plk1 poses a compelling site to block the Plk1 function. The first identified small-molecule compound, Poloxin, shows its high specificity by aiming at the PBD of Plk $1,{ }^{16}$ which is directly followed by another inspiring report that purpurogallin (PPG), a benzotropolone-containing natural compound derived from nutgalls, also blocks the PBD of Plk1 with selectivity. ${ }^{39}$ The data demonstrate that inhibition of the PBD is sufficient to specifically interfere with the multiple functions of PIk1.

Herein, we further characterize the phenotype and effect induced by Poloxin. Poloxin-treated cells display centrosome fragmentation, an aberrant mitotic spindle, and chromosome misalignment (Figure 1), which activate the mitotic checkpoint (Figure 3), further leading to prolonged mitosis (see Supplemental Figure S1 at http:// ajp.amjpathol.org), followed by strong induction of apoptosis (Figure 4). Moreover, centrosome fragmentation induced by Poloxin can be attributed, at least in part, to dysfunction of a centrosomal protein, Kiz (Figure 2). More important, Poloxin strongly inhibits proliferation of a panel of proliferating cells (Figure 5, Table 1). More interestingly, Poloxin significantly suppresses tumor growth in xenograft mice (Figure 6, A and B). We found a low proliferation rate and an increased induction of apoptosis in tumor tissues after 5 to 6 weeks of treatment with Poloxin (Figure 6C; see also Supplemental Figure S4, B and $\mathrm{C}$, at $h$ ttp://ajp.amjpathol.org). The data highlight that Poloxin works in vitro and in vivo by specifically interfering with the functions of Plk1, leading to mitotic prolongation and apoptosis induction.

It is well established that the function of PIk 1 is required for centrosome maturation, separation, and spindle pole integrity. ${ }^{24,40,41}$ We have observed a distinctive centrosomal fragmentation with aberrant mitotic spindles in cells treated with Poloxin (Figure 1, A and D, and Figure 2, B and C). Notably, centrosomes were unfocused and distanced in cells treated with another PBD inhibitor, PPG. ${ }^{39}$ Moreover, cells treated with a pan-PBD inhibitor, poloxipan, also displayed fragmented centrosomes. ${ }^{42}$ However, enforced PBD expression did not impair centrosome maturation/separation. ${ }^{43,44}$ It will be interesting to clarify whether overexpression of the PBD also induces centrosome fragmentation.
We have closely looked into possible mechanisms for centrosomal fragmentation induced by Poloxin. It has been convincingly reported that Plk1 associates with Kiz, an important centrosomal substrate for Plk1, in a PBDdependent manner and regulates its function for centrosome integrity by phosphorylating its residue, T379. ${ }^{23}$ Blocking this regulation or depletion of Kiz causes fragmentation and dissociation of the pericentriolar material from centrioles at prometaphase, which will be not able to endure the forces that converge on centrosomes during spindle formation. ${ }^{23}$ Based on these data, we reasoned that Kiz could be one of the centrosomal key molecules affected by Poloxin. This notion is underlined by the results that Kiz T379E, the phosphomimetic form of Kiz, is capable of partially rescuing the Poloxin-induced centrosomal fragmentation (Figure 2), indicating that Plk1-mediated Kiz function is disrupted by Poloxin. Because Plk1 is involved in centrosome stability and centriole cohesion during mitosis, ${ }^{45}$ it will be important to clarify the molecular mechanisms of centrosome fragmentation and to explore further critical molecules, such as aster-associated protein (ASAP), ${ }^{46}$ that are responsible for spindle pole integrity and could be affected by Poloxin. Nevertheless, the data suggest that Poloxin is specifically targeting the Plk1 function at centrosomes in cells.

In addition to HeLa cells, Poloxin strongly inhibits the proliferation of a panel of human cancer cell lines from diverse organ derivations (Table 1). The $\mathrm{EC}_{50}$ ranges from 15 to $35 \mu \mathrm{mol} / \mathrm{L}$. The proliferation of exponentially normal growing cells, such as human retinal primary epithelial cells, human umbilical vein endothelial cells, mammary epithelial (MTSV-1) cells, and fibroblasts, is also suppressed by Poloxin; $\mathrm{EC}_{50}$ values range from 20 to $30 \mu \mathrm{mol} / \mathrm{L}$, implying a comparable sensitivity of nontransformed cycling cells to Plk1 inhibition. This phenomenon has already been observed with BI 2536 treatment. ${ }^{47}$ Furthermore, apoptosis was strongly induced in normal rat kidney cells and $\mathrm{NIH} / 3 \mathrm{~T} 3$ cells on treatment with the PBD inhibitor, PPG. ${ }^{39}$ Therefore, we suppose that Plk1 is required for the proliferation of both normal/nontransformed cells and tumor cells. Thus, the Plk1 inhibitors, targeting either the protein kinase domain, such as BI 2536, or the PBD domain of Plk1, such as Poloxin and PPG, affect both cancer cells and nontransformed but proliferating cells with a comparable efficacy, at least in cell culture system. Yet, this does not necessarily represent situations in vivo because these nontransformed cells are artificially kept in cycling by additionally supplementing various growth factors. In addition, we are aware that these results from the small-molecule compounds are not consistent with previous data ${ }^{31,48}$ that knockdown of Plk 1 by small-interfering RNA inhibits proliferation more dramatically in cancer cells than in normal cells. Different time courses could possibly result in this discrepancy: small-molecule compounds, such as BI 2536 or Poloxin, work immediately within cells on addition, whereas smallinterfering RNA requires some time to deplete Plk1. During this period, normal cells with intact checkpoints could have enough time to respond to the challenges induced by depleting Plk1 by activating corresponding rescue pathways, such as halting the cell cycle, and to survive 
the challenges. This is not the case for tumor cells. Alternatively, depletion of PIk1 by small-interfering RNA is not able to totally knock out PIk1 and the remaining Plk1 may not be sufficient for survival of Plk1-addicted cancer cells, but for normal cells. This is in accordance with a recent report ${ }^{49}$ that sensitivity of normal cells to Plk1 depletion is dependent on the depletion level. However, an interesting review by Lens et al ${ }^{50}$ suggests that it is unlikely to have Plk1-addicted cells, and the contribution of Plk1 to tumor formation might be largely due to the induction of chromosome instability. Thus, the efficacy of Plk1 inhibitors most probably primarily depends on their antimitotic effect in tumor cells, whereas depleting Plk1 generates a form of cellular stress in primary cells and causes cells to arrest during $G_{2}$. Yet, it still cannot explain why the small-molecule compounds, such as BI 2536 and Poloxin, exert comparable efficacy in both normal proliferating cells and tumor cells. Further studies (in particular, evidence from primary cells and tumor tissues in vivo) are required to precisely answer this question. Moreover, although Poloxin shows a higher specificity toward the PBD of Plk1 than that of Plk2 and Plk3 in vitro, it is important to define whether it interferes with the functions of Plk2 and Plk3 in vivo. It will also be critical to delineate the relationship between Poloxin and Plk5, the only PBD protein. All these data will shed light on the application strategy of small-molecule compounds targeting Plk1.

Taken together, in this study, we have further characterized the PBD inhibitor Poloxin and demonstrated, for the first time to our knowledge, its effectiveness in xenograft models. We believe that inhibitors specifically targeting the PBD, such as Poloxin and PPG, hold much promise for developing a new generation of molecular anti-mitotic agents, although many challenges are posed by their clinical development.

\section{Acknowledgments}

We thank Drs. Tadashi Yamamoto and Miho Ohsugi (Institute of Medical Science, University of Tokyo) for offering the Myc- and HA-tagged wild-type Kiz plasmids and their variants, Kiz T379A and Kiz T379E, for this study; and Drs. Kenneth W. Kinzler and Bert Vogelstein (Ludwig Center at Johns Hopkins, Howard Hughes Medical Institute, Baltimore, MD) for the HCT116 p53 ${ }^{-1-}$ cell line.

\section{References}

1. Barr FA, Sillje HH, Nigg EA: Polo-like kinases and the orchestration of cell division. Nat Rev Mol Cell Biol 2004, 5:429-440

2. Archambault V, Glover DM: Polo-like kinases: conservation and divergence in their functions and regulation. Nat Rev Mol Cell Biol 2009, 10:265-275

3. Andrysik Z, Bernstein WZ, Deng L, Myer DL, Li YQ, Tischfield JA, Stambrook PJ, Bahassi EM: The novel mouse Polo-like kinase 5 responds to DNA damage and localizes in the nucleolus. Nucleic Acids Res 2010, 38:2931-2943

4. de Cárcer G, Escobar B, Higuero AM, Garcia L, Ansón A, Pérez G, Mollejo M, Manning G, Meléndez B, Abad-Rodríguez J, Malumbres M: Plk5, a polo box domain-only protein with specific roles in neuron differentiation and glioblastoma suppression. Mol Cell Biol 2011, 31:1225-1239

5. Strebhardt K: Multifaceted polo-like kinases: drug targets and antitargets for cancer therapy. Nat Rev Drug Discov 2010, 9:643-660

6. Golsteyn RM, Mundt KE, Fry AM, Nigg EA: Cell cycle regulation of the activity and subcellular localization of Plk1, a human protein kinase implicated in mitotic spindle function. J Cell Biol 1995, 129:16171628

7. Lee KS, Yuan YL, Kuriyama R, Erikson RL: PIk is an M-phase-specific protein kinase and interacts with a kinesin-like protein, $\mathrm{CHO} 1 /$ MKLP-1. Mol Cell Biol 1995, 15:7143-7151

8. Arnaud L, Pines J, Nigg EA: GFP tagging reveals human Polo-like kinase 1 at the kinetochore/centromere region of mitotic chromosomes. Chromosoma 1998, 107:424-429

9. Elia AE, Rellos P, Haire LF, Chao JW, Ivins FJ, Hoepker K, Mohammad D, Cantley LC, Smerdon SJ, Yaffe MB: The molecular basis for phosphodependent substrate targeting and regulation of Plks by the Polo-box domain. Cell 2003, 115:83-95

10. Yun SM, Moulaei T, Lim D, Bang JK, Park JE, Shenoy SR, Liu F, Kang YH, Liao C, Soung NK, Lee S, Yoon DY, Lim Y, Lee DH, Otaka A, Appella E, McMahon JB, Nicklaus MC, Burke TR Jr, Yaffe MB, Wlodawer A, Lee KS: Structural and functional analyses of minimal phosphopeptides targeting the polo-box domain of polo-like kinase 1. Nat Struct Mol Biol 2009, 16:876-882

11. Strebhardt K, Ullrich A: Targeting polo-like kinase 1 for cancer therapy. Nat Rev Cancer 2006, 6:321-330

12. Smith MR, Wilson ML, Hamanaka R, Chase D, Kung H, Longo DL, Ferris DK: Malignant transformation of mammalian cells initiated by constitutive expression of the polo-like kinase. Biochem Biophys Res Commun 1997, 234:397-405

13. van de Weerdt BC, Medema RH: Polo-like kinases: a team in control of the division. Cell Cycle 2006, 5:853-864

14. Xie S, Wu H, Wang Q, Cogswell JP, Husain I, Conn C, Stambrook P, Jhanwar-Uniyal M, Dai W: Plk3 functionally links DNA damage to cell cycle arrest and apoptosis at least in part via the p53 pathway. J Biol Chem 2001, 276:43305-43312

15. Smith P, Syed N, Crook T: Epigenetic inactivation implies a tumor suppressor function in hematologic malignancies for Polo-like kinase 2 but not Polo-like kinase 3. Cell Cycle 2006, 5:1262-1264

16. Reindl W, Yuan J, Kramer A, Strebhardt K, Berg T: Inhibition of polo-like kinase 1 by blocking polo-box domain-dependent proteinprotein interactions. Chem Biol 2008, 15:459-466

17. Kreis NN, Sommer K, Sanhaji M, Krämer A, Matthess Y, Kaufmann M, Strebhardt K, Yuan J: Long-term downregulation of Polo-like kinase 1 increases the cyclin-dependent kinase inhibitor p21(WAF1/CIP1). Cell Cycle 2009, 8:460-472

18. Yuan J, Kramer A, Matthess Y, Yan R, Spankuch B, Gatje R, Knecht R, Kaufmann M, Strebhardt K: Stable gene silencing of cyclin B1 in tumor cells increases susceptibility to taxol and leads to growth arrest in vivo. Oncogene 2006, 25:1753-1762

19. Kreis NN, Sanhaji M, Krämer A, Sommer K, Rödel F, Strebhardt K, Yuan J: Restoration of the tumor suppressor p53 by downregulating cyclin B1 in human papillomavirus 16/18-infected cancer cells. Oncogene 2010, 29:5591-5603

20. Sanhaji M, Friel CT, Kreis NN, Kramer A, Martin C, Howard J, Strebhardt K, Yuan J: Functional and spatial regulation of mitotic centromere-associated kinesin by cyclin-dependent kinase 1. Mol Cell Biol 2010, 30:2594-2607

21. Yarm FR: Plk phosphorylation regulates the microtubule-stabilizing protein TCTP. Mol Cell Biol 2002, 22:6209-6221

22. Feng Y, Hodge DR, Palmieri G, Chase DL, Longo DL, Ferris DK: Association of polo-like kinase with alpha-, beta- and gamma-tubulins in a stable complex. Biochem J 1999, 339(Pt 2):435-442

23. Oshimori N, Ohsugi M, Yamamoto T: The Plk1 target Kizuna stabilizes mitotic centrosomes to ensure spindle bipolarity. Nat Cell Biol 2006, 8:1095-1101

24. van Vugt MA, van de Weerdt BC, Vader G, Janssen $H$, Calafat J, Klompmaker R, Wolthuis RM, Medema RH: Polo-like kinase- 1 is required for bipolar spindle formation but is dispensable for anaphase promoting complex/Cdc20 activation and initiation of cytokinesis. J Biol Chem 2004, 279:36841-36854

25. Santamaria A, Neef R, Eberspacher U, Eis K, Husemann M, Mumberg D, Prechtl S, Schulze V, Siemeister G, Wortmann L, Barr FA, Nigg EA: Use of the novel PIk1 inhibitor ZK-thiazolidinone to elucidate functions 
of Plk1 in early and late stages of mitosis. Mol Biol Cell 2007, 18:4024-4036

26. Lenart P, Petronczki M, Steegmaier M, Di FB, Lipp JJ, Hoffmann M, Rettig WJ, Kraut N, Peters JM: The small-molecule inhibitor BI 2536 reveals novel insights into mitotic roles of polo-like kinase 1. Curr Biol 2007, 17:304-315

27. Elowe S, Hummer S, Uldschmid A, Li X, Nigg EA: Tension-sensitive Plk1 phosphorylation on BubR1 regulates the stability of kinetochore microtubule interactions. Genes Dev 2007, 21:2205-2219

28. Wong OK, Fang G: PIX1 is the $3 F 3 / 2$ kinase responsible for targeting spindle checkpoint proteins to kinetochores. J Cell Biol 2005, 170: 709-719

29. Ahonen LJ, Kallio MJ, Daum JR, Bolton M, Manke IA, Yaffe MB, Stukenberg PT, Gorbsky GJ: Polo-like kinase 1 creates the tensionsensing 3F3/2 phosphoepitope and modulates the association of spindle-checkpoint proteins at kinetochores. Curr Biol 2005, 15: 1078-1089

30. Liu X, Erikson RL: Polo-like kinase (PIk)1 depletion induces apoptosis in cancer cells. Proc Natl Acad Sci U S A 2003, 100:5789-5794

31. Liu X, Lei M, Erikson RL: Normal cells, but not cancer cells, survive severe Plk1 depletion. Mol Cell Biol 2006, 26:2093-2108

32. Yim H, Erikson RL: Polo-like kinase 1 depletion induces DNA damage in early S prior to caspase activation. Mol Cell Biol 2009, 29:26092621

33. Yuan J, Kramer A, Eckerdt F, Kaufmann M, Strebhardt K: Efficient internalization of the polo-box of polo-like kinase 1 fused to an Antennapedia peptide results in inhibition of cancer cell proliferation. Cancer Res 2002, 62:4186-4190

34. Gali-Muhtasib H, Ocker M, Kuester D, Krueger S, El-Hajj Z, Diestel A, Evert M, El-Najjar N, Peters B, Jurjus A, Roessner A, Schneider-Stock $\mathrm{R}$ : Thymoquinone reduces mouse colon tumor cell invasion and inhibits tumor growth in murine colon cancer models. J Cell Mol Med 2008, 12:330-342

35. Jackson JR, Patrick DR, Dar MM, Huang PS: Targeted anti-mitotic therapies: can we improve on tubulin agents? Nat Rev Cancer 2007, 7:107-117

36. Schmit TL, Ledesma MC, Ahmad N: Modulating polo-like kinase 1 as a means for cancer chemoprevention. Pharm Res 2010, 27:989-998

37. Degenhardt $Y$, Lampkin $\mathrm{T}$ : Targeting Polo-like kinase in cancer therapy. Clin Cancer Res 2010, 16:384-389

38. Schoffski P: Polo-like kinase (PLK) inhibitors in preclinical and early clinical development in oncology. Oncologist 2009, 14:559-570
39. Watanabe N, Sekine T, Takagi M, Iwasaki J, Imamoto N, Kawasaki H, Osada H: Deficiency in chromosome congression by the inhibition of Plk1 polo box domain-dependent recognition. J Biol Chem 2009, 284:2344-2353

40. Lane HA, Nigg EA: Antibody microinjection reveals an essential role for human polo-like kinase 1 (Plk1) in the functional maturation of mitotic centrosomes. J Cell Biol 1996, 135:1701-1713

41. Sumara I, Gimenez-Abian JF, Gerlich D, Hirota T, Kraft C, de la Torre C, Ellenberg J, Peters JM: Roles of polo-like kinase 1 in the assembly of functional mitotic spindles. Curr Biol 2004, 14:1712-1722

42. Reindl W, Yuan J, Krämer A, Strebhardt K, Berg T: A pan-specific inhibitor of the polo-box domains of polo-like kinases arrests cancer cells in mitosis. Chembiochem 2009, 10:1145-1148

43. Seong YS, Kamijo K, Lee JS, Fernandez E, Kuriyama R, Miki T, Lee KS: A spindle checkpoint arrest and a cytokinesis failure by the dominant-negative polo-box domain of Plk1 in U-2 OS cells. J Biol Chem 2002, 277:32282-32293

44. Hanisch A, Wehner A, Nigg EA, Sillje HH: Different Plk1 functions show distinct dependencies on Polo-Box domain-mediated targeting. Mol Biol Cell 2006, 17:448-459

45. Wang $X$, Yang Y, Duan Q, Jiang N, Huang Y, Darzynkiewicz Z, Dai W: sSgo1, a major splice variant of Sgo1, functions in centriole cohesion where it is regulated by PIk1. Dev Cell 2008, 14:331-341

46. Eot-Houllier G, Venoux M, Vidal-Eychenié S, Hoang MT, Giorgi D, Rouquier S: Plk1 regulates both ASAP localization and its role in spindle pole integrity. J Biol Chem 2010, 285:29556-29568

47. Steegmaier M, Hoffmann M, Baum A, Lenart P, Petronczki M, Krssak M, Gurtler U, Garin-Chesa P, Lieb S, Quant J, Grauert M, Adolf GR, Kraut N, Peters JM, Rettig WJ: BI 2536, a potent and selective inhibitor of polo-like kinase 1, inhibits tumor growth in vivo. Curr Biol 2007, 17:316-322

48. Spankuch-Schmitt B, Bereiter-Hahn J, Kaufmann M, Strebhardt K: Effect of RNA silencing of polo-like kinase-1 (PLK1) on apoptosis and spindle formation in human cancer cells. J Natl Cancer Inst 2002, 94:1863-1877

49. Lei M, Erikson RL: Plk1 depletion in nontransformed diploid cells activates the DNA-damage checkpoint. Oncogene 2008, 27:39353943

50. Lens SM, Voest EE, Medema RH: Shared and separate functions of polo-like kinases and aurora kinases in cancer. Nat Rev Cancer 2010, 10:825-841 